\title{
ALTERACIONES PERIODONTALES: DIAGNÓSTICO Y PLANIFICACIÓN DE TRATAMIENTO
}

\author{
Periodontal diseases: diagnosis and treatment planning
}

\begin{abstract}
Astudillo Sisalima José 1 , Correa Carrera Katherine ${ }^{2}$, Castillo Jiménez Dayana ${ }^{3}$, Nicolalde Baquerizo Jorge
${ }^{1}$ Odontólogo - Especialista en Periodoncia e Implantología ${ }^{2}$ Odontóloga - Maestría Universitaria en Dirección y Gestión Sanitaria ${ }^{3}$ Odontóloga, Consulta Privada, Cuenca. Ecuador. ${ }^{3}$ Odontólogo, Consulta Privada, Cuenca. Ecuador.

DOI: https://doi.org/10.31984/oactiva.v6i3.474
\end{abstract}

\section{Resumen}

Se presenta la presente guía de conceptos básicos centrada en el área de periodoncia para estudiantes de pregrado enfatizando ideas clave para un adecuado diagnóstico y planificación óptima del tratamiento, además la guía recopila los principales contenidos para la preparación del examen de acreditación profesional en Ecuador.

Palabras Clave: Diagnóstico, Encía, Epitelio, Gingivitis, Periodontitis (DeCS)

\section{Abstract}

This guide to basic concepts focused on the periodontics area for undergraduate students is presented, emphasizing key ideas for a proper diagnosis and optimal treatment planning. In addition, the guide compiles the main contents for the preparation of the professional accreditation exam in Ecuador.

Key Words: Diagnosis, Gingiva, Epithelium, Gingivitis, Periodontitis (DeCS)

\section{Introducción}

Una de las enfermedades bucales más comunes en los seres humanos es la enfermedad periodontal que se clasificaba hasta el año 2017 en gingivitis y periodontitis. La Organización Mundial de la Salud (OMS) ha indicado que el $10 \%$ de la población mundial padece de periodontitis grave pudiendo generar pérdida dental ${ }^{(1)}$. La gingivitis se considera una forma temprana de enfermedad periodontal, cuya característica principal es la inflamación de las encías y el sangrado al sondaje gingival, en cambio la periodontitis se desarrolla con el tiempo por la acumulación de placa bacteriana, da lugar a una simbiosis bacteriana, que desencadena la formación de bolsas periodontales, recesión de las encías, destrucción de tejidos y pérdida de hueso alveolar, que en última instancia puede conducir a la pérdida dentaria. El tratamiento periodontal, puede retrasar la progresión de la enfermedad al eliminar placa bacteriana alrededor de los dientes y reducir la inflamación, una vez que se produce la pérdida de inserción, esta es irreversible y permanente. ${ }^{(2)}$ Los determinantes principales de la susceptibilidad a la periodontitis incluyen factores como: higiene bucodental deficiente, tabaquismo, factores sistémicos y factores genéticos. ${ }^{(3)}$

Un correcto diagnóstico y una adecuada planificación del tratamiento de pacientes con enfermedad periodontal son requisitos fundamentales para lograr un control exitoso de la enfermedad a largo plazo. Dentro de la elaboración del diagnóstico y planificación del tratamiento no se puede omitir la valoración del examen clínico y radiográfico. El examen clínico radica en la recolección de datos que permitan completar el periodontograma del paciente. Por otra parte, con el examen radiográfico se puede verificar si existe o no pérdida ósea (en el caso de existir, se determina su severidad), así como también la presencia de otros factores que puedan predisponer el progreso de esta enfermedad. Adicionalmente se puede solicitar un examen microbiológico, con el objeto de conocer la microbiota y posteriormente prescribir el antibiótico ideal para el caso de ser necesario. ${ }^{(4)}$ 
El tratamiento periodontal busca detener el proceso inflamatorio, reducir el sangrado, disminuir la profundidad de sondaje y mejorar el nivel de inserción, este tratamiento incluye una etapa sistémica y una etapa mecánica. La etapa sistémica verifica la presencia de enfermedades que pueden agravar la enfermedad periodontal, al mismo tiempo se encarga de modificar hábitos inadecuados como el tabaquismo. En la etapa mecánica se remueve el biofilm supragingival y subgingival, además se realiza un raspado y alisado radicular de las superficies radiculares para la eliminación de bolsas periodontales, para posteriormente instruir al paciente respecto a técnicas de higiene bucodental y control de factores que ocasionan la retención de placa bacteriana. Durante esta etapa se busca lograr una microbiota que sea compatible con la salud periodontal, no obstante, puede ser necesaria una etapa quirúrgica para conseguir un buen estado de salud periodontal. ${ }^{(4)} \mathrm{El}$ objetivo de este artículo es presentar información para los estudiantes de pregrado sobre alteraciones periodontales, su diagnóstico y planificación del tratamiento, y como guía de estudio para la preparación del examen de acreditación profesional.

\section{Estado del arte}

Es importante conocer las características y conceptos básicos de los componentes del periodonto para identificar las diferentes alteraciones que se presentan en estos tejidos de soporte, se denomina periodonto al conjunto de tejidos conformados por encía, hueso alveolar, cemento radicular y ligamento periodontal. La mucosa oral está constituida por tres zonas; la mucosa masticatoria constituida por la encía y el revestimiento del paladar duro, la mucosa especializada constituida por el dorso de la lengua y la mucosa bucal que cubre el resto de la cavidad bucal. ${ }^{(5,6)}$

La encía recubre la apófisis alveolar y rodea el cuello de todos los dientes tanto temporales como permanentes, compuesta por epitelio queratinizado, estratificado, escamoso en la mayoría de sus partes y adherido a una base de tejido conectivo, la cual es menos celular, que incluye el aparato de fibras supra alveolares, vasos sanguíneos, linfáticos y nervios. Esta adquiere su forma y textura definitiva con la erupción de los dientes. La encía es de color rosa coral, se extiende desde el límite amelocementario hasta la línea mucogingival, termina a nivel coronal en el margen gingival libre con un contorno festoneado o plano, mientras que en sentido apical se continúa con la mucosa alveolar laxa, de color rojo oscuro de la cual se separa por la línea mucogingival. En el paladar no se presenta esta línea ya que el paladar duro y la apófisis alveolar están revestidos por el mismo tipo de mucosa. ${ }^{(5,6)}$
Su función principal es de protección de las estructuras profundas permitiendo el intercambio selectivo con el ambiente de la cavidad oral, además de inserción, la encía se divide en encía libre, que se extiende desde la línea amelocementaria hasta el fondo del surco gingival y encía adherida que se extiende desde el fondo del surco hasta la línea mucogingival, por otra parte la papila interdentaria posee una forma piramidal, cubriendo el nicho entre diente y diente, con una profundidad al sondaje de 1 a $2,5 \mathrm{~mm}$ al existir mayor cantidad de tejido, la papila interdentaria se pierde al existir ausencia de la cresta ósea y puntos de contacto. ${ }^{(5,6)}$

\section{Características de la encía en condiciones normales}

- No se presenta características de inflamación ni sangrado al sondaje.

- Textura debe ser lisa y brillante con una superficie finamente punteada con aspecto a cascara de naranja.

- Color rosa pálido, sin embargo, en algunos individuos una mayor cantidad de melanina da como resultado una variación de este color rosa.

- Debe ubicarse a nivel del límite amelocementario.

Microscópicamente encontramos diferentes tipos de epitelios, el epitelio bucal, que cubre la superficie exterior de la encía libre e insertada, se extiende desde el margen gingival hasta la unión mucogingival, epitelio del surco que recubre la pared blanda del surco gingival y epitelio de unión que es un epitelio indiferenciado, escamoso, estratificado no queratinizado y una de sus características excepcionales es su alta tasa de rotación celular por lo que su recuperación se lleva a cabo en 5 días aproximadamente, las células que permiten la inserción del epitelio de unión al diente se denominan hemidesmosomas estos forman un sello biológico que impide el ingreso de bacterias. ${ }^{(5,6)}$

El tejido conectivo del periodonto se clasifica en tejidos blandos, ligamento periodontal y el tejido conectivo supracrestal y tejidos duros como el cemento y hueso alveolar; la principal función es permitir la fijación de la pieza dental dentro del alveolo y protección del hueso del medio bucal externo, el tejido conectivo supracrestal se denomina también lámina propia y se encuentra conformada por una capa papilar subyacente y una capa reticular contigua, posee un compartimiento celular conformado por fibroblastos $(5 \%)$, y otro extracelular compuesto por fibras colágenas $60 \%$, nervios, vasos, y matriz extracelular (35\%). 
Su función principal es la de proteger la superficie radicular y el hueso alveolar del medio externo, fija el diente dentro de su alveolo y proporciona soporte a los tejidos epiteliales. ${ }^{(5,6)}$

Los fibroblastos se encargan de la producción de fibras y de sintetizar la matriz del tejido conectivo.

Las fibras gingivales se caracterizan por establecer la unión de la encía adherida además aporta resistencia a la encía ante las fuerzas masticatorias, existen 4 tipos de fibras:

- Colágenas: Predominan en tejido conectivo supracrestal, se disponen transversalmente, constituidas por fibras principales (transeptales, circulares, dentoperiosticas, alveologingivales, dentogingivales) y fibras secundarias (interpapilares, transgingivales, intercirculares, intergingivales, semicirculares, periostiogingivales).

- Reticulares: Presentes en tejido conectivo laxo, rodean pequeños vasos sanguíneos.

- Oxitalano: Abundantes en ligamento periodontal, escasas en encía.

- Elásticas: Se encuentran en asociación con pequeños vasos sanguíneos.

La Matriz extracelular es la sustancia fundamental que ocupa el espacio en el cual están incluidas fibras y células, es amorfa y posee un contenido elevado de agua. Es producida principalmente por fibroblastos. Se compone de macromoléculas de carbohidratos y proteínas, generalmente proteoglicanos, principalmente ácido hialurónico, y glicoproteínas, sobre todo fibronectina. Su función es encargarse del trasporte de nutrientes y agua hacia el tejido conectivo. ${ }^{(5,6)}$

El Cemento Radicular (CR) es un tejido mineralizado especializado que se encuentra recubriendo las superficies radiculares, posee fibras colágenas incluidas en una matriz orgánica, su contenido mineral está dado por la hidroxiapatita, el cemento cumple la función de inserción de las fibras del ligamento periodontal contribuyendo en el proceso de reparación cuando el área periodontal ha sido afectada, las diferentes formas de cemento son ${ }^{(5,6)}$ :

- Cemento acelular de fibras extrínsecas (CAFE): Situado tercio superior de las superficies radiculares en la porción coronal conteniendo haces de las fibras de Sharpey constituyendo un aparato de inserción que conecta el diente con el hueso alveolar, este tipo de cemento se remueve al realizar un pulido y alisado radicular.
- Cemento celular de fibras intrínsecas: Está distribuido a lo largo del tercio apical o la mitad apical de la raíz y en las áreas de furcación contiene cementocitos y fibras intrínsecas.

- Cemento celular mixto: Se localiza en el tercio apical de las superficies radiculares conformada por fibras extrínsecas e intrínsecas.

El Ligamento Periodontal (LP) es un tejido blando altamente vascularizado que rodea las raíces de las piezas dentarias, conecta el cemento radicular con la pared del alvéolo, desempeña funciones de inserción, desarrollo y mantención del tejido conectivo, transporte nutritivo y metabólico, además de permitir la inervación sensitiva de las piezas dentales, esta inervación confiere la capacidad de receptar estímulos de tacto, dolor, presión y propiocepción. El ligamento periodontal se encuentra conformado por fibras (Cuadro 1) que en condiciones de reposo permiten un pequeño movimiento de la pieza dental dentro del alveolo, de esta misma forma los mecanoreceptores se activan principalmente ante los estímulos de presión y tacto ${ }^{(5,6)}$ (Figura 1).

Cuadro 1: Tipos de Fibras Periodontales.

Fibras Periodontales

1. Fibras de la cresta alveolar: Aseguran la pieza dental en el alveolo, resisten fuerzas laterales.

2. Fibras Horizontales: Limita movimientos laterales.

3. Fibras Oblicuas: Son las más abundantes, limitan los movimientos en dirección apical.

4. Fibras Apicales: Resisten fuerzas de luxación, protegiendo vasos sanguíneos y fibras nerviosas.

5. Fibras Interradiculares: presente en piezas multirradiculares.

El ligamento periodontal (LP) es indispensable para la movilidad de las piezas dentarias, esta movilidad está determinada por la altura, espesor y calidad del ligamento periodontal, la literatura señala que este espesor puede variar entre $0,2 \mathrm{~mm}$ y $0,4 \mathrm{~mm}$, la presencia del LP durante la masticación permiten que las fuerzas generadas sean distribuidas adecuadamente, se describen a continuación los diferentes grados de movilidad dental. ${ }^{(6)}$

- Grado 1: Movimiento fisiológico de 0,25mm en sentido vertical.

- Grado 2: Movimiento de $+0,25 \mathrm{~mm}$ y $-1 \mathrm{~mm}$ en sentido horizontal y vertical.

- Grado 3: Movimiento de $+1 \mathrm{~mm}$ en sentido vertical y horizontal. 
Las células del LP son principalmente fibroblastos, osteoblastos, cementoblastos, osteoclastos y de la misma manera la presencia de células epiteliales y fibras nerviosas.

El Hueso Alveolar (HA) se forma a partir de la apófisis alveolar tanto del maxilar superior como de la mandíbula. El proceso alveolar es aquel hueso de los maxilares que contiene las cavidades (alvéolos) para alojar los dientes. Este proceso se compone de hueso del haz que se forma en capas en una orientación paralela a la dirección corono-apical del diente. Se desarrolla en conjunto con el desarrollo y la erupción de los dientes y está formado por células del folículo dental y células que son independientes del desarrollo dentario. Consta de placas corticales externas (vestibular, lingual y palatina) de hueso compacto, una esponjosa central y el hueso que reviste los alvéolos (hueso alveolar). Las fibras de Sharpey se extienden oblicuamente desde la fina lámina de hueso que recubre la pared de la cavidad y son continuas con las fibras del ligamento periodontal., el hueso alveolar, junto al cemento y ligamento periodontal constituyen el órgano de inserción de las estructuras dentarias. ${ }^{(5,6)}$

El Espacio Biológico está conformado por el surco gingival, el epitelio de unión y tejido conectivo, este al ser invadido puede provocar retracción gingival y retracción ósea causando hipersensibilidad y alteraciones estéticas (Figura 1), se puede realizar una evaluación del espacio biológico tanto de manera clínica como radiográfica.

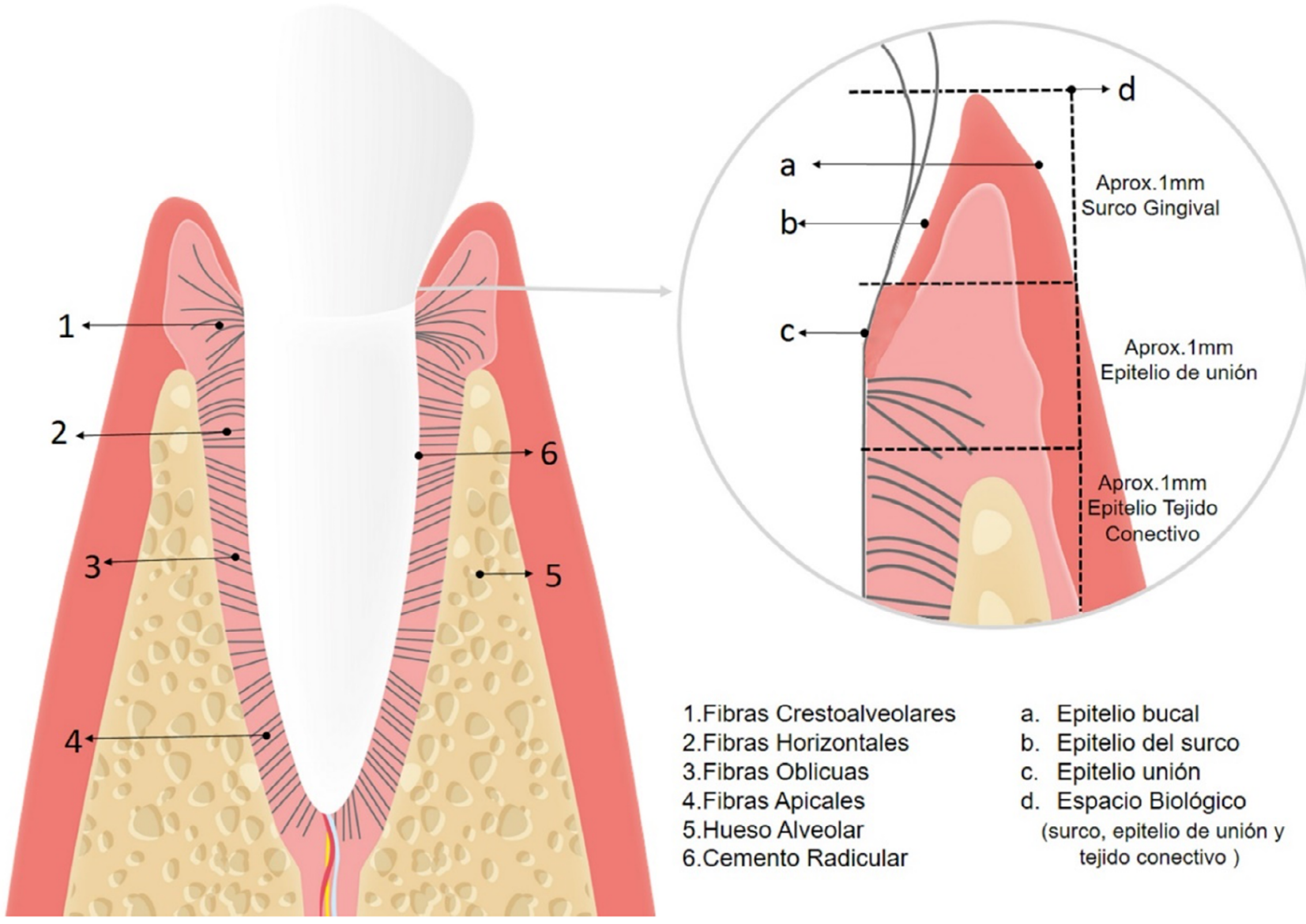

Figura 1: Estructuras Periodontales Nota: Diagramación realizada por los autores. 
Microorganismos Periodontales: La placa bacteriana en un estado inicial se presenta como una película trasparente e incolora, que se adhiere a la superficie del diente, compuesta por diversas bacterias, aproximadamente 200 tipos, y células descamadas, además de leucocitos, macrófagos, que generalmente se encuentran dentro de una matriz de proteínas y polisacáridos. La formación de esta placa se inicia con el depósito de una película acelular, que es colonizada en los primeros dos días por microrganismos aerobios gram positivos como Actinomyces Viscosus y Streptococcus Sanguis, luego se comienza una etapa de transición hacia especies facultativas Gram positivas, posteriormente se desarrolla un medio privado de oxígeno donde surgirán microrganismos anaerobios Gram negativos. Los colonizadores secundarios se adhieren a otras especies mediante el proceso denominado "coagregación" como: Prevotella Intermedia, Capnocytophaga, Fusobacterium nucleatum, Porphyromonas Gingivalis. Existen factores que permiten la colonización del tejido, es así como principalmente Porphyromonas Gingivalis actúa de manera directa o indirecta sobre los tejidos periodontales, causando daño tisular. La invasión de bacterias en los tejidos periodontales causa ulceraciones o perforaciones de los espacios intercelulares del epitelio como principales responsables y con mayor evidencia tenemos al Aggregatibacter Actinomycetemcomitans Y Porphyromonas Gingivalis. Cuando las bacterias se encuentran adheridas a los tejidos, estas usan varias estrategias para evadir las acciones de defensa del huésped.

\section{Diagnóstico de alteraciones periodontales}

El diagnóstico oportuno es esencial para un adecuado tratamiento, es importante en primer lugar establecer si existe enfermedad periodontal, luego identificar su tipo, magnitud, distribución y gravedad, determinar su causa, factores predisponentes y factores desencadenantes. ${ }^{(7)}$

La literatura señala que las distintas enfermedades que afectan a los tejidos de soporte del diente se pueden agrupar en 3 grandes categorías:

- Enfermedades Gingivales.

- Tipos de Periodontitis

- Manifestaciones Periodontales asociadas a enfermedades sistémicas.

El diagnóstico debe englobar una valoración general del paciente así como de la cavidad oral, este se constituye posterior al análisis del caso (examen clínico, radiográfico, sondaje periodontal etc.), con una valoración de los signos y síntomas ${ }^{(7,8,9)}$ (Cuadro 2).

Los parámetros clínicos periodontales se establecen en la evaluación de:

- Profundidad al sondaje.

- Nivel de inserción clínica.

- Sangrado al sondaje.

- Movilidad dental.

- Progresión de la enfermedad periodontal.

- Pérdida ósea radiográfica.

Evaluando cada uno de los parámetros que se han identificado en la consulta se puede establecer que tipo de enfermedad periodontal está afectando al paciente, además se considerará localizada cuando afecte menos del $30 \%$ de piezas analizadas, o generalizada cuando afecta más del $30 \%$, se debe determinar la pérdida de inserción y la presencia de alguna enfermedad sistémica o hábito (tabaquismo) que estén relacionadas con el desarrollo de la enfermedad, posteriormente se podrá establecer un correcto tratamiento. $^{(7,8)}$

A partir del año 1999 mundialmente se utilizaba la clasificación dispuesta por la Asociación Americana de Periodoncia (AAP) tomando como factor causal la placa bacteriana, señalando la existencia de gingivitis, periodontitis crónica y periodontitis agresiva, sin embargo, desde el año 2018 se han modificado algunos criterios otorgados por la AAP y la Federación Europea de Periodoncia ${ }^{(10,11,12)}$ (Figura 2). 
Cuadro 2. Etapas del Diagnóstico Clínico Periodontal

\section{PRIMERA ETAPA \\ - Valoración general del paciente \\ - Anamnesis}

\section{Historia Clínica:}

- Enfermedades sistémicas (cardiovasculares, hematológicos, endocrinos, enfermedades hemáticas, inmunodeficiencias etc.)

- Infecciones que influyen en el desarrollo de enfermedades y trastornos sistémicos.

- Antecedentes de atenciones médicas (hospitalizaciones, medicamentos administrados, tendencias hemorrágicas, alergias etc.)

\section{Antecedentes Dentales:}

- Tratamiento previo.

- Motivo de Consulta (enfermedad actual, naturaleza, duración, ausencia o presencia de dolor, sangrado al cepillado.)

\section{Estudio Radiográfico :}

- Rx periapicales.

- Rx de aleta de mordida.

- Rx panorámica.

\section{Modelos de estudio:}

- Registran la ubicación del margen gingival y posición dentaria.

- Permiten efectuar comparaciones pre y post terapéuticas.

\section{Fotografías Clínicas}

Examen Bucal :

\section{SEGUNDA ETAPA}

- Valoración de la Higiene bucal.

- Halitosis (GUNA-caracterizada por un olor fétido)

- Examinar paladar, piso de la boca, lengua, saliva etc.

\section{Examen de las estructuras dentarias:}

- Presencia de caries.

- Anomalías de desarrollo y forma.

- Desgastes dentales (erosión, abrasión, atrición)

- Pigmentaciones Dentales

- Hipersensibilidad

- Contactos proximales

- Movilidad dental (desplazamiento fisiológico aprox. de 0,2mm)

- Oclusión

- Sensibilidad a la percusión

\section{Examen de los ganglios linfáticos:}

- Generalmente los inflamados aumentan de tamaño, son palpables y sensibles al tacto.

\section{Examen Periodontal :}

- Evaluar color, consistencia, contorno, posición y textura de la encía.

- Presencia o ausencia de inflamación, placa y cálculo supra gingival.

- Sangrado al sondaje

- Bolsas periodontales

- Recesiones Gingivales

- Perdida de Hueso Alveolar

- Supuraciones

- Absceso gingival (encía marginal), absceso periodontal (abarca estructuras de soporte del periodonto) y abscesos periapicales.

Sistema de Detección :

- PSR (Periodontal Screening \& Recording)*

\section{Exámenes complementarios:}

- Estado Nutricional.

- Análisis de Sangre.

NOTA: *La Asociación Dental Americana desarrolló el sistema de detección y registro llamado PSR (Periodontal Screening \& Recording) con el objetivo de reconocer y detectar el estado periodontal actual del paciente, dividiendo a la cavidad bucal en seis sextantes, con una sonda periodontal de extremo esferoidal de $0,5 \mathrm{~mm}$ se examina seis puntos alrededor de cada diente, tres en la zona vestibular y tres en la zona lingual o palatina. 
Figura 2: Criterios de Diagnóstico-Asociación Americana de Periodoncia

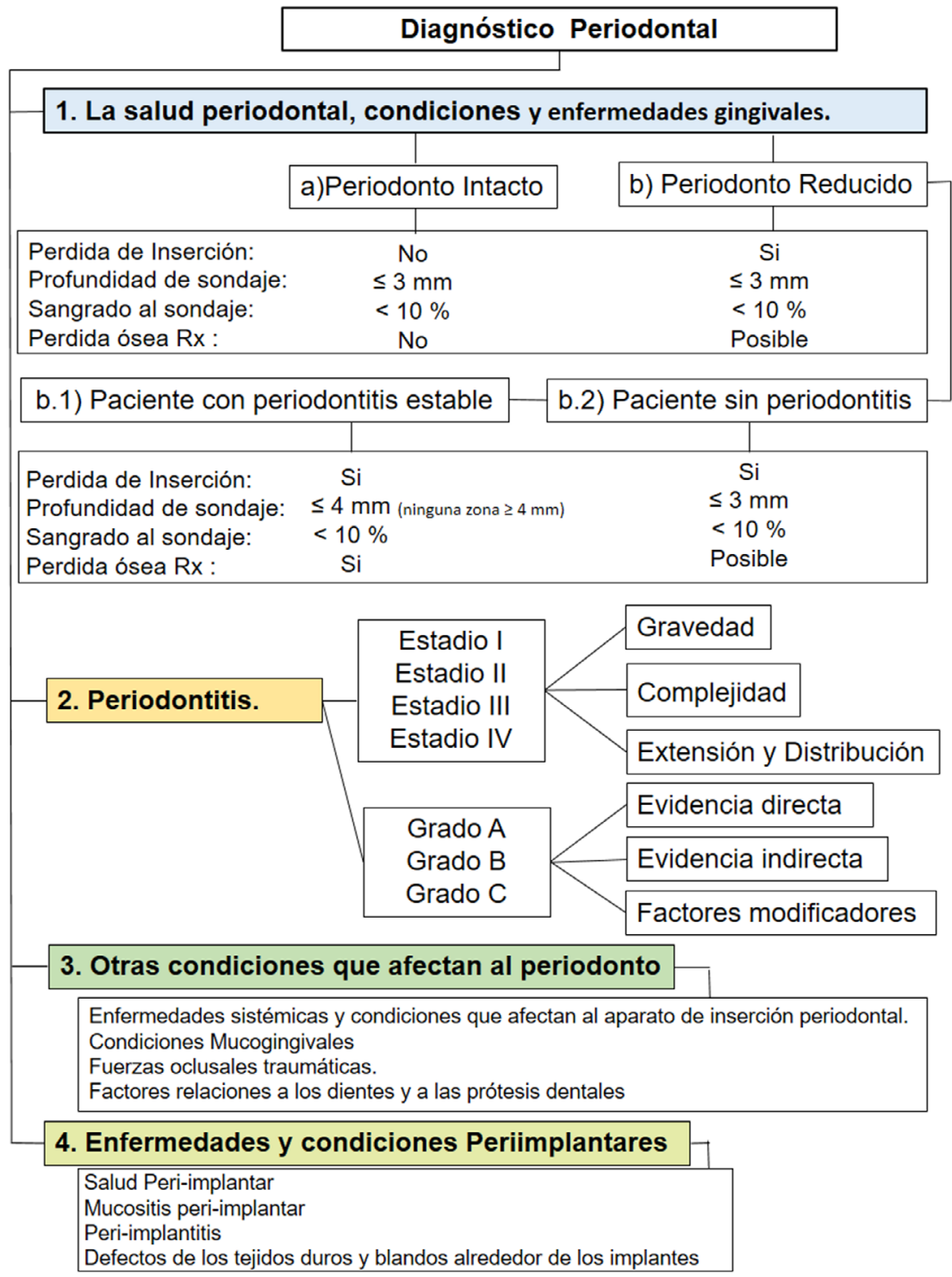

Nota: Adaptado de Chapple, Mealey, van Dyke y cols 2018.

Diagramación de figura 2 realizada por los autores

\section{Planificación del tratamiento}

Después de diagnosticar una enfermedad periodontal y conocer los microorganismos que la producen es importante desarrollar un adecuado tratamiento, preservando la salud bucal. ${ }^{(10)}$

Esta planificación se divide en dos partes:

a) Plan terapéutico total: Se busca coordinar los procedimientos corrigiendo las afecciones causantes de la enfermedad periodontal, eliminar inflamación, irritantes radiculares y bolsas. ${ }^{(11)}$

b) Procedimientos terapéuticos: Para el tratamiento en cada paciente las secuencias de las fases de tratamiento dependerán de las exigencias de cada caso $^{(12)}$ (Cuadro 3). 


\section{CUADRO 3: Fases de Tratamiento}

\begin{tabular}{lc}
\hline & Fases del Tratamiento Periodontal \\
\hline Fase preliminar & Tratamiento de urgencia. \\
& $-\quad$ Dental o periapical. \\
& $-\quad$ Periodontal. \\
Fase I (etiotrópica) & Otros (extracción de dientes con pronóstico \\
& Control de placa y educación al paciente. \\
Fase II (quirúrgica) & Evaluación de inflamación gingival, bolsa periodontal, \\
Fase III (restaurativa) & Placa y cálculo. \\
Fase IV (mantenimiento) & Restauraciones y rehabilitación. \\
& Instrucción al paciente. \\
& Visitas periódicas de control, donde se evaluará: \\
& $-\quad$ Placa bacteriana. \\
& $-\quad$ Cálculo dental. \\
& - Oclusión, movilidad dentaria. \\
& - Otros cambios patológicos. \\
\hline
\end{tabular}

\section{Conclusión}

Se ha recopilado sistemáticamente la información más importante tomando en cuenta la bibliografía establecida por el Consejo de Aseguramiento de la Calidad de la Educación Superior (CACES) para los estudiantes de pregrado, como una guía de preparación para el examen de acreditación profesional.

\section{Agradecimientos}

Un agradecimiento especial al Dr. Ebingen Villavicencio Caparó, por su dirección y además al Departamento de Investigación de la Unidad Académica de Ciencia Odontológica de la Universidad Católica de Cuenca-Ecuador.

\section{Bibliografía}

1. Organización Mundial de la Salud. Salud bucodental. [Online].; 2020 [cited 20200602 . Available from: https://www.who.int/es/news-room/fact-sheets/ detail/oral-health.

2. Michaud D, Fu Z, Shi J, Chung M. Periodontal Disease, Tooth Loss, and Cancer Risk. Epidemiologic Reviews. 2017 Enero; 39(1).

3. Raitapuro T, Molleson T, Hughes F. The prevalence of periodontal disease in a Romano-British population c. 200-400 AD. British Dental Journal. 2014 October; 217(8).

4. Peña M, Vaamonde C, Vilarrasa J, Vallés C, Pascual A, Shapira L, et al. Diagnóstico y tratamiento de las enfermedades periodontales: de lo imposible a lo posible. Revista científica de la Sociedad Española de Periodoncia. 2018; 4(11).

5. Lindhe J, Thorkild K, Niklaus P. Periodontologia Clínica e Implantología Odontológica/ Clinical Periodontology and Implant Dentistry. Quinta ed. Buenos Aires: Médica Panamericana; 2009.
6. Carranza F, Cervera C, Newman M, Ramos J. Periodontología clínica. Octava ed. México: McGraw-Hill Interamericana; 1998.

7. Lindhe J, Nyman S. The effect of plaque control and surgical pocket elimination on the establishment and maintenance of periodontal health. A longitudinal study of periodontal therapy in cases of advanced disease. Journal of clinical periodontology. 1975 April; 2(2).

8. Goldman H. Gengivectomy: indications, contraindications and methods. Am J Orthodont Oral Surg. 1964; 32(5).

9. Gómez A, Ocampo A, Vieira A, Herazo B, Ruiz C. Fundamentos de la odontología: Periodoncia. Segunda ed. Bogotá: Pontificia Universidad Javeriana; 2007.

10. Chapple I, Mealey B, Van Dyke T, Bartold P, Dommisch H, Eickholz P, et al. Periodontal health and gingival diseases and conditions on anintact and a reduced periodontium: Consensus report ofworkgroup 1 of the 2017 World Workshop on the Classification of Periodontal and Peri-Implant Diseases and Conditions. 2018; 89(1).

11. Herrera D, Figuero E, Shapira L, Jin L, Sanz M. La nueva clasificación de las enfermedades periodontales y periimplantarias. Sociedad Española de Periodoncia. 2018; 5(11).

12. Sánchez J, Carvalho G, Spin J. Nueva Clasificación sobre las Enfermedades y Condiciones Periodontales y Peri-implantares: Una Breve Reseña. Odontología. 2018; 20(2).

Recibido: 30 de septiembre de 2020

Aceptado: 28 de abril de 2021 